Research Article

\title{
Initial Hypotheses for Modeling and Numerical Analysis of Rockfill and Earth Dams and Their Effects on the Results of the Analysis
}

\author{
Mohammad Rashidi (iD) ${ }^{1}$ and Habib Rasouli $\mathbb{D D}^{2}$ \\ ${ }^{1}$ Department of Civil Engineering, University of Texas at El Paso, El Paso, TX, USA \\ ${ }^{2}$ Department of Civil Engineering, University of Technology Sydney, Sydney, NSW, Australia \\ Correspondence should be addressed to Mohammad Rashidi; mrashidi@miners.utep.edu
}

Received 16 August 2017; Accepted 28 May 2018; Published 22 July 2018

Academic Editor: Evangelos J. Sapountzakis

Copyright (c) 2018 Mohammad Rashidi and Habib Rasouli. This is an open access article distributed under the Creative Commons Attribution License, which permits unrestricted use, distribution, and reproduction in any medium, provided the original work is properly cited.

\begin{abstract}
Since the behavior of earth dams is unreliable in different stages of construction, impounding, and exploitation, this matter is an unavoidable and essential issue with regard to the serious dangers caused by the failure of these important structures. It is crucial to evaluate the behavior of dams and examine the consistency between the carried out analyses and the behavioral parameters under different conditions in the lifespan of dams due to the uncertainty of the principles and hypotheses which have been adopted to analyze these structures. This objective will be accomplished through the help of correct numerical analyses. A series of hypotheses are adopted to simplify the parametric analyses before starting these analyses. The aim of this research is to develop and discuss these hypotheses. And so, the number of elements and their effects on the results of analyses were examined through the consolidation of unsaturated soil method, the compressible fluid method, correlated analysis, and uncorrelated analysis. It became clear after the numerical analyses that correlated analysis is a more precise method in comparison with the uncorrelated analysis method. However, this method is not economical when it comes to high dams and the replacement method is the uncorrelated analysis. Furthermore, the displacements are not that sensitive to the bulk modulus of water while the maximum settlement of the dam transfers from the middle of the dam's core to a location higher than that the core as the bulk modulus of water increases. However, pore water pressure is very sensitive to the bulk modulus of water.
\end{abstract}

\section{Introduction}

The advancement of engineering science regarding analyzing and designing geotechnical structures has presented the answers to many questions posed about these structures based on the theoretical and experimental findings. The development of numerical methods (such as the finite element method) and the behavioral models of the materials under different loading conditions (static and dynamic) has made it possible to more practically examine the geotechnical behavior under different loading conditions through considering different types of boundary conditions and the effect of numerous parameters. It is clear that the accuracy and the degree to which the results obtained from these types of analyses are close to the actual values greatly depend on the parameters of the behavioral model which govern the materials being actual.

Rockfill dams, as one of the greatest geotechnical structures, are increasingly used because of their inherent flexibility, capacity to absorb large seismic energy, and their adaptability to various foundation conditions. The use of modern earth and rockfill moving equipment and locally available materials makes such dams economical as well. Rockfill materials contain particles of large sizes, and their testing requires equipment of formidable dimensions. Therefore, the sizes of particles for testing are reduced, usually using modeling techniques. Four modeling techniques are available: the scaling technique [1], the parallel gradation technique [2], the generation of the quadratic grain-curve technique [3], and the replacement technique [4]. Among them, the parallel 


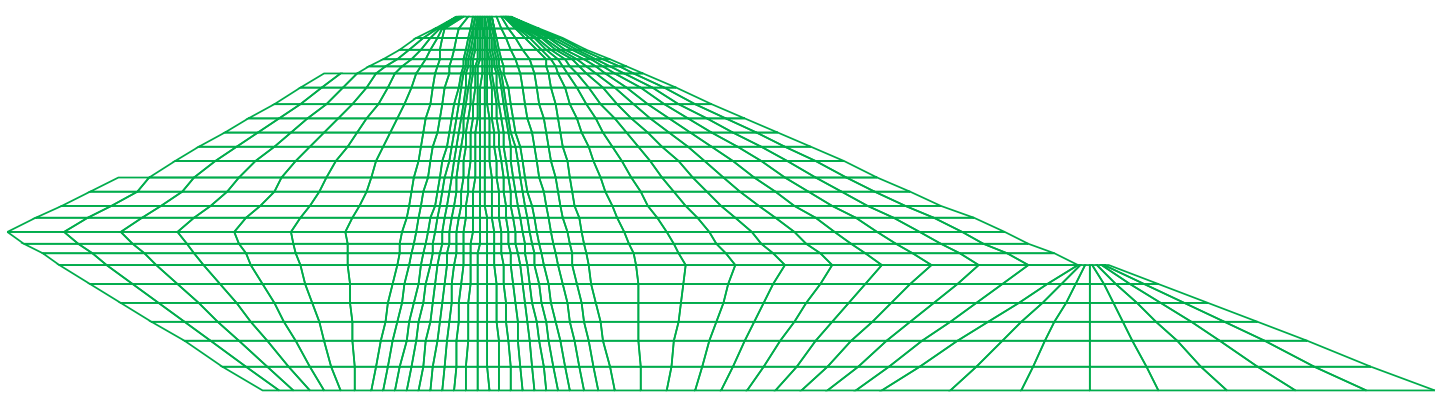

(a)

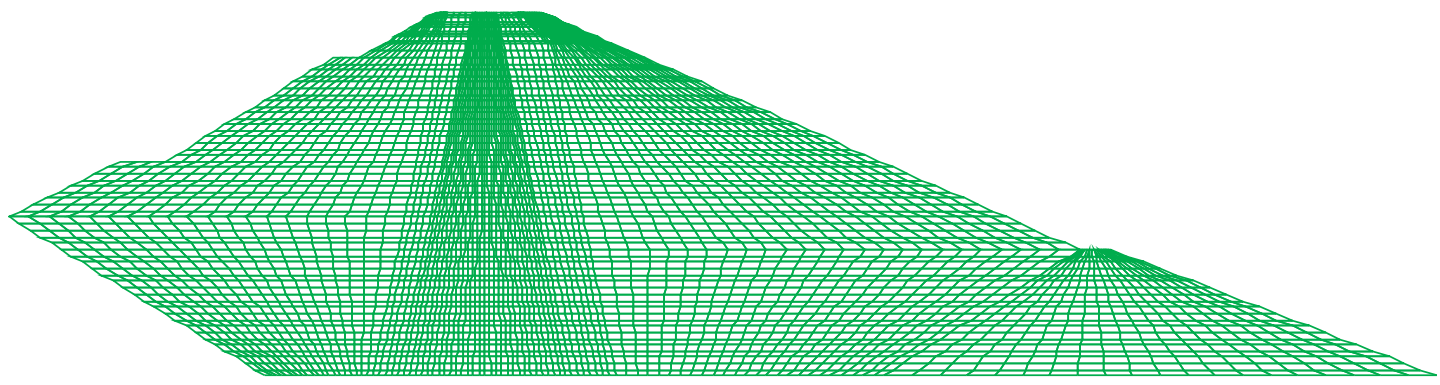

(b)

FIgURE 1: First and second samples' meshing. (a) Coarse mesh size (1300 elements). (b) Fine mesh size (7200 elements).

gradation technique has been considered the most appropriate by Ramamurthy and Gupta [5].

Valstad et al. [6] analyzed the Storvatn dam located in Norway using a Newmark approach. Their studies indicated that shearing off of the thin core near the crest may have occurred under severe shaking. Hoeg [7] presented the results of Storvatn dam and showed that relatively large shear strains may occur in the top of the core if dam slopes are very steep. However, he concluded that in general, rockfill dams with asphaltic concrete core have favorable seismic protection. Meintjes and Jones [8] analyzed the Ceres dam located in South Africa by using the Newmark method. The predicted behavior of the dam was satisfactory. Rashidi and Haeri [9] by using finite differences method performed numerical analysis of the Gavoshan Dam located in Iran. They observed that the dam's performance was suitable regarding the created pore water pressure and hydraulic fracturing probability in the construction period as well as during the first impounding. Rashidi et al. [10] performed a comparison between numerical analysis and monitoring of a Siah-Sang earth Dam. Comparing the obtained results of the numerical analysis with the measured values in the dam indicated that there is a proper consistency between the results of numerical analysis and instrumentation. Salemi and Baziar [11] performed some numerical and experimental tests for Meyjaran dam in Iran with a height of $60 \mathrm{~m}$. They concluded that the asphalt concrete core behaves safely, even under very severe earthquake. There are other related studies [12-14] that conducted numerical analysis on rockfill dams and earth structures. The results of these studies showed the appropriate response of the earth dams and structure during and after an earthquake.

Based on the above background, this paper studies the initial hypotheses for numerical analysis of rockfill and earth dams as well as their effects on the results of the analysis. Then, it introduces examining the degree of accuracy of the number of elements in the results of numerical analysis. Finally, it presents selecting the method of examining the consolidation of unsaturated soil method and examining the uncorrelated analysis of stress, strain, and pore water pressure.

\section{Examining the Degree of Accuracy of the Number of Elements in the Results of Numerical Analysis}

In order to clarify the effects of total number of elements on the accuracy of numerical analysis and results, two different types of model were considered. The properties of the materials and their geometric shape are in accordance with Gavoshan Dam which is a rockfill dam with a clay core and 122 meters high. The first sample which could be seen in Figure 1 has a coarse mesh size with 1300 elements. The number of its layers are equal to the number of the elements in the vertical direction in the numerical computation, also in the time of construction, which means its vertical displacements will be equal to zero after every layer is constructed. Similarly, to the real construction time, the vertical displacement of all the elements will be zero once.

The second sample has a finer mesh size with 7200 elements. The time the program needs to run is very longer for the second sample. The number of its layers is 26 at the time of construction, similar to the first sample. The difference between them, however, is that each layer has a number of rows of vertical elements on top of each other, and after each layer is run, only the top element's vertical displacement will be equal to zero; this will lead to the vertical displacement or the dam settlement results being disorderly, fluctuated, and 


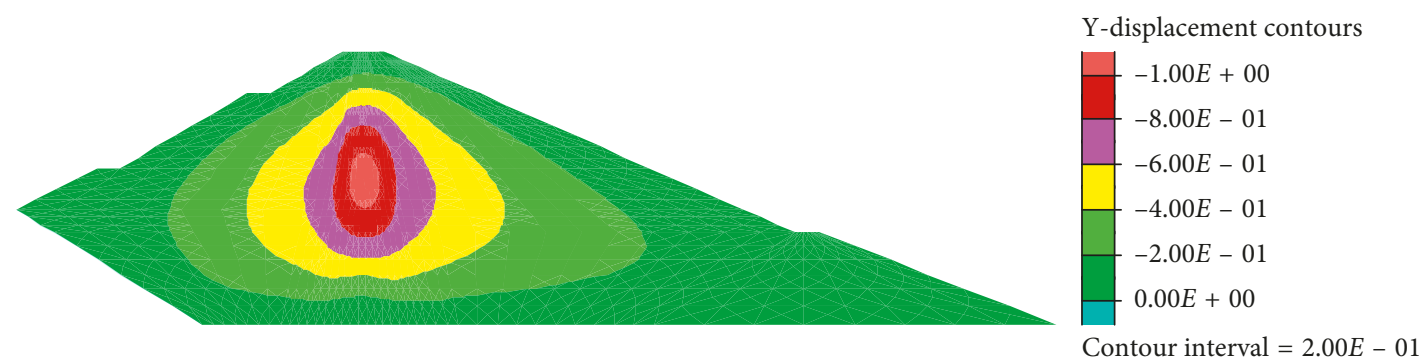

(a)

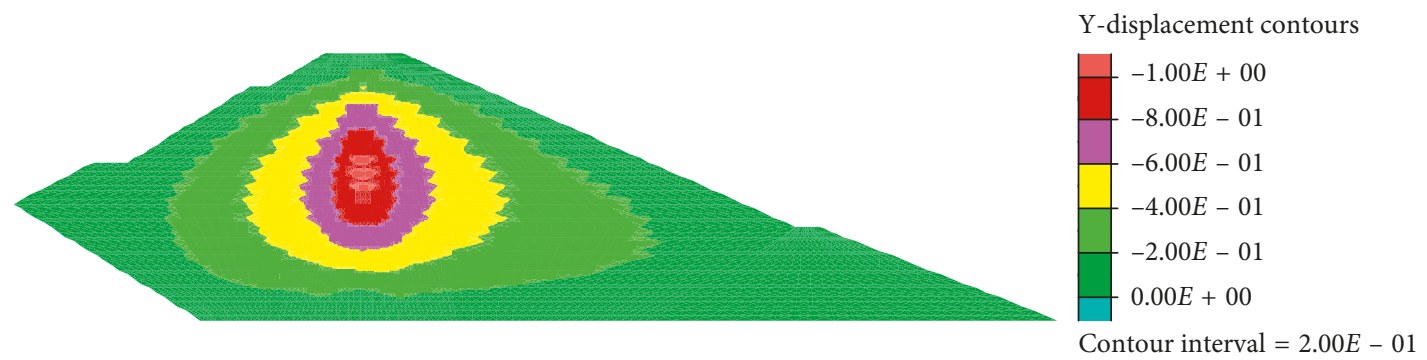

(b)

Figure 2: Vertical displacement of the first and the second samples. (a) Coarse mesh size. (b) Fine mesh size.

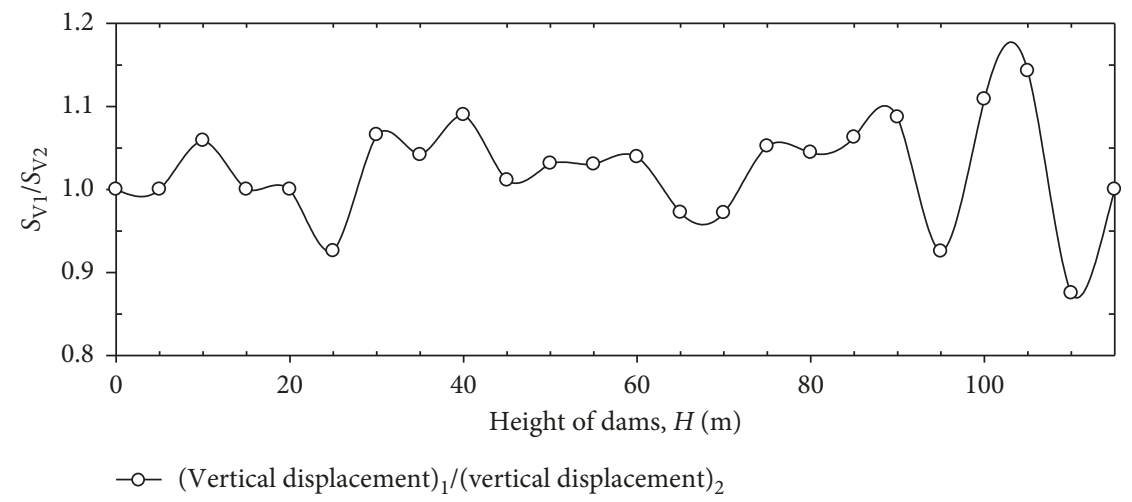

Figure 3: Ratio of the vertical displacement of the first sample to the vertical displacement of the second sample.

unreal. Figure 2 shows the difference between settlement in the first and the second samples.

The obtained results were presented in the ratio of the total vertical stress, pore water pressure, and vertical displacement of the first sample to those of the second sample in the middle of the core in the entire height of the dam. In the first part of the study, the vertical displacement ratio of the first sample to that of the second sample was conducted. The smaller the layers are, the more the dam settles. It is expected for the second sample to display more settlement since the elements are smaller, and as a result, it is expected the settlement ratio of the first to the second sample to be smaller than one. As it could be seen in Figure 3, the settlement ratio is absolutely unorderly, and the reason is only the settlement occurring in the second sample since the vertical displacements of the upper layers, which their displacement has become zero, are not in harmony with the upper and lower layers which have not become zero, and the software shows lesser of its displacement. The first sample is therefore more acceptable than the second sample.

In the model with the large elements, the total vertical stress and pore water pressure obtained from numerical analysis are slightly greater than that of exact sample with finer elements. Figure 4 which shows the ratio of pore water pressure and total vertical stress of the first sample to that of the second sample expresses the same thing. However, this difference is insignificant and could be overlooked. Generally, examining the effects of elements' number on the accuracy of numerical analyses made it clear that making the elements finer, increasing elements' number from 1300 elements to 7200 elements, decreased the total vertical stress ratio and pore water pressure ratio about 2 and 3 percent, respectively, while the vertical displacement ratio increased about 4 percent.

As specified in Figures 5 and 6, vertical displacements and pore water pressure ratio of the first and second are 


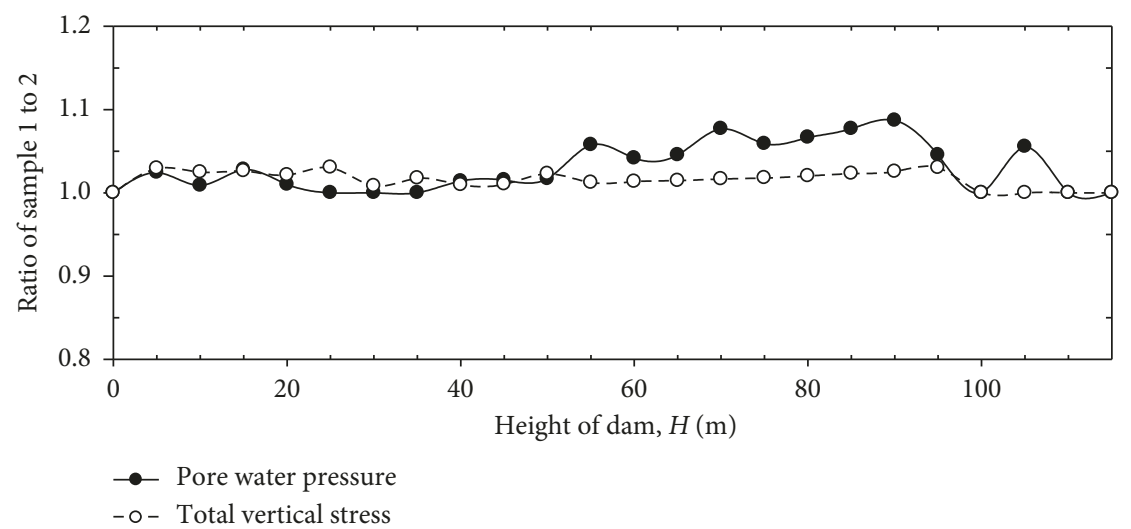

FIGURE 4: Pore water pressure ratio and total vertical stress ratio of the first sample to those of the second sample.

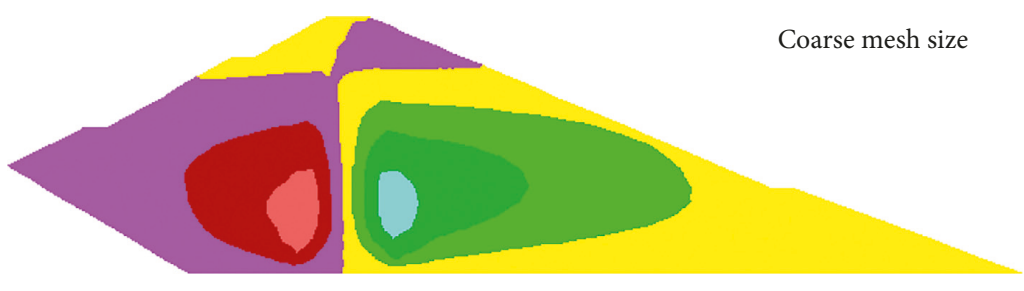

(a)

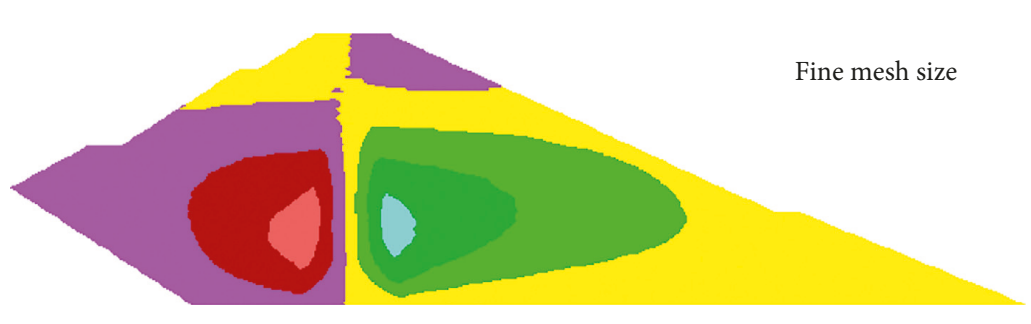

(b)

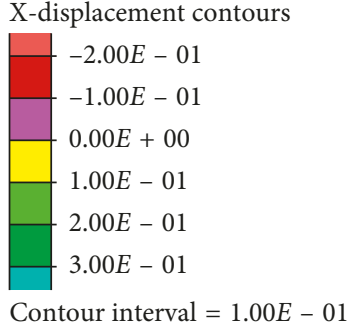

$\mathrm{X}$-displacement contours

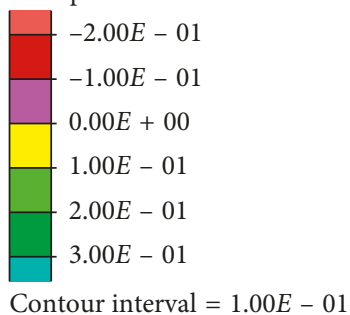

Contour interval $=1.00 E-01$

Figure 5: Vertical displacement of samples one and two. (a) Coarse mesh size. (b) Fine mesh size.

totally similar regarding the form of the curves as well as the quantity. Therefore, it is better to use the first sample in order to accelerate the computations and also to better show the changes in the vertical displacements.

\section{Selecting the Method of Examining the Consolidation of Unsaturated Soil Method}

There are two methods for examining the behavior of unsaturated substances during construction and impounding: consolidation of unsaturated soil method and compressible fluid method. The type of the case study and also the instructions of the software must be considered when selecting one of these methods. However, since there is no need for many parameters and the computations do not take long and also we assume a saturation degree higher than $80 \%$ for the earth core of the dam, which is not an irrational assumption, it is better to consider the second method to examine the unsaturated behavior of the soil. It is necessary to obtain the equivalent bulk modulus of liquid-air phase in order to use this method. This is done through calculating and drawing the $R_{\mathrm{u}}$ values in the core for different bulk modulus and selecting the most suitable curve among them. With regard to the fact that the value of the bulk modulus of water is equal to $2 e 9 \mathrm{~Pa}$ under real conditions, parametric examinations have been conducted on bulk modules from $1 e 7$ to $1 e 8 \mathrm{~Pa}$; therefore, the equivalent bulk modulus can be selected. On the other hand, since the bulk modulus values also rely on confining pressure [15], the bulk modulus could also be increased in the dam height. The graphs of Figure 7 indicate different status of $R_{\mathrm{u}}$ for different equivalent bulk modulus.

As it could be seen in the figure, the greater the values of the bulk modulus of water, the greater value of $R_{\mathrm{u}}$. The settlement and the pore water pressure of this dam were also examined thorough parametric examination in order to 


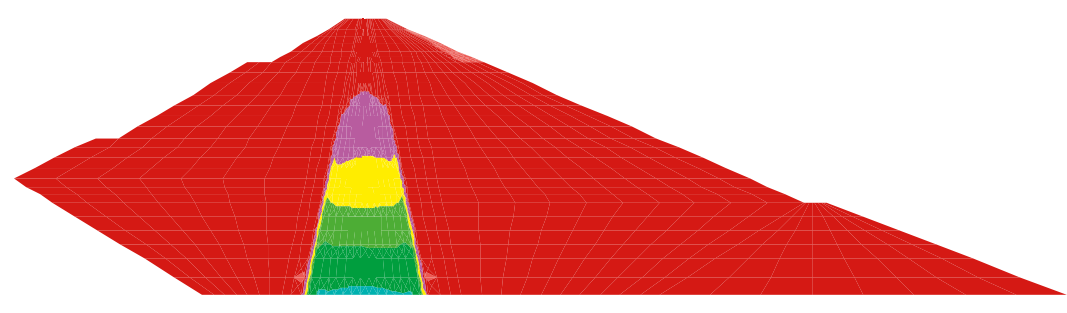

(a)

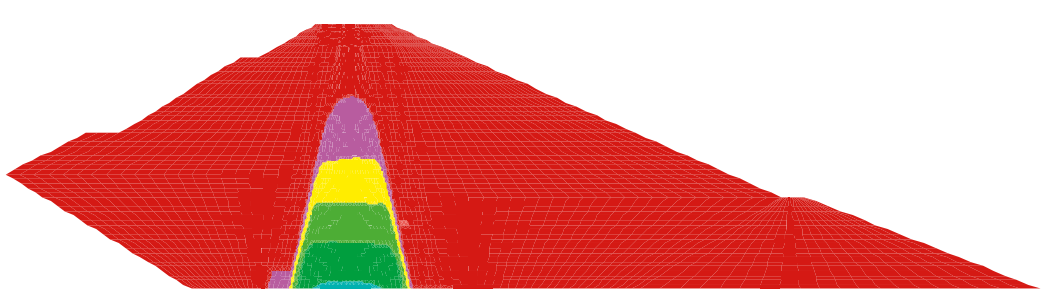

(b)
Pore pressure contours

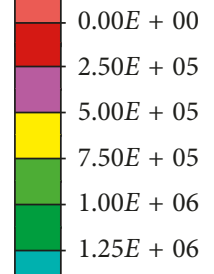

Contour interval $=2.50 E+05$

Pore pressure contours

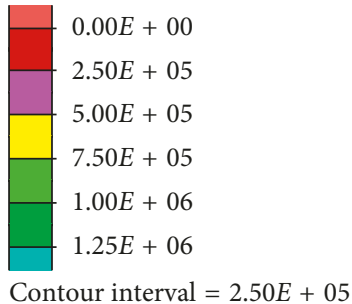

Figure 6: Pore water pressure ratio of the first and the second sample. (a) Coarse mesh size. (b) Fine mesh size.

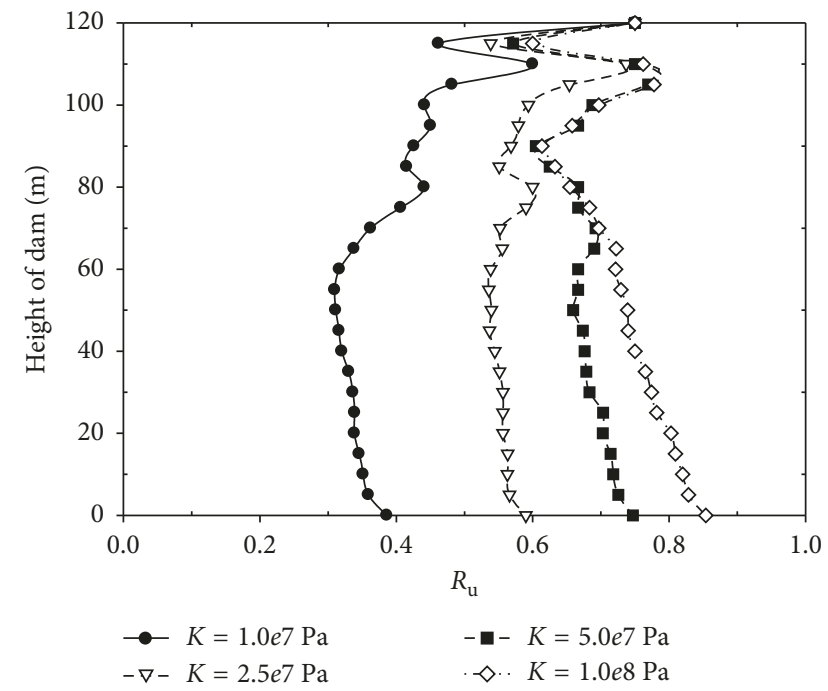

Figure 7: Comparing $R_{\mathrm{u}}$ values for different bulk modulus of water.

select the bulk modulus accurately. Figures 8 and 9 illustrate the displacement and pore water pressure of different bulk modulus.

These graphs indicate that the displacements are not very sensitive to the bulk modulus of water. Only the maximum settlement of the dam transfers to a location higher than the middle of the core as the bulk modulus of water increases while pore water pressure is extremely sensitive to bulk modulus of water.

\section{Examining the Uncorrelated Analysis of Stress and Train and Pore Water Pressure}

Using the consolidation of correlated equations and equations involved in mechanical stress and strain and water

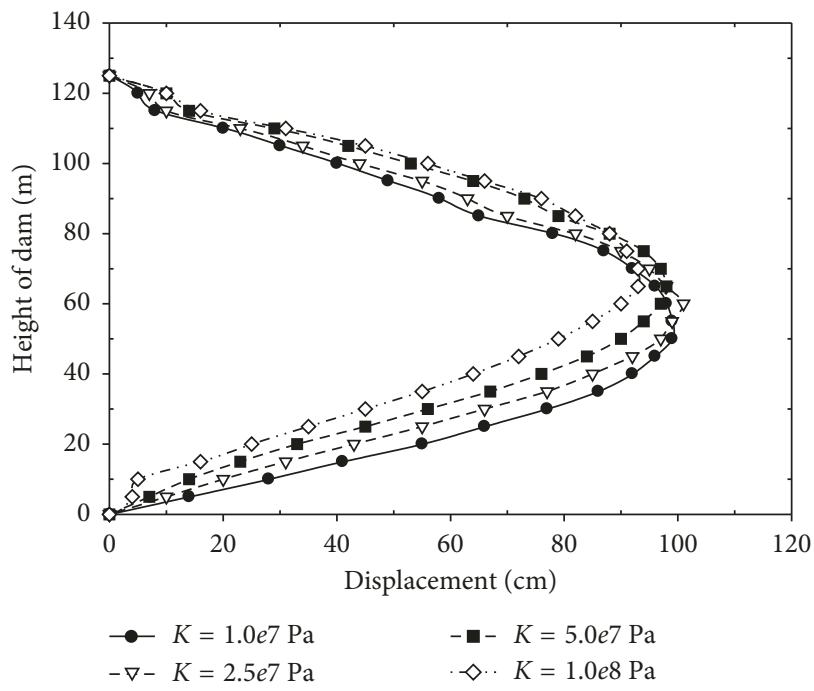

FIgURE 8: Comparing the displacement values in the middle of the core for different bulk modulus of water.

pressures are precise methods for examining the behavior of the soil environment in presence of water flow. Correlated analysis needs a lot of time and computational effort in order to be executed and for results to be obtained, and also the run-time increases progressively as the number of the nodes increases. Therefore, it is not economical to execute the analyses. Another method which has a decreased level of quantitative accuracy but decreases the run-time and the computational method is uncorrelated solution in each stage of the analysis progress. In other words, the equilibrium and behavioral relationship equations are first analyzed in each layer of construction and impounding without considering water flow, and so the displacements and strains are obtained. The pore water pressure will be determined in each 


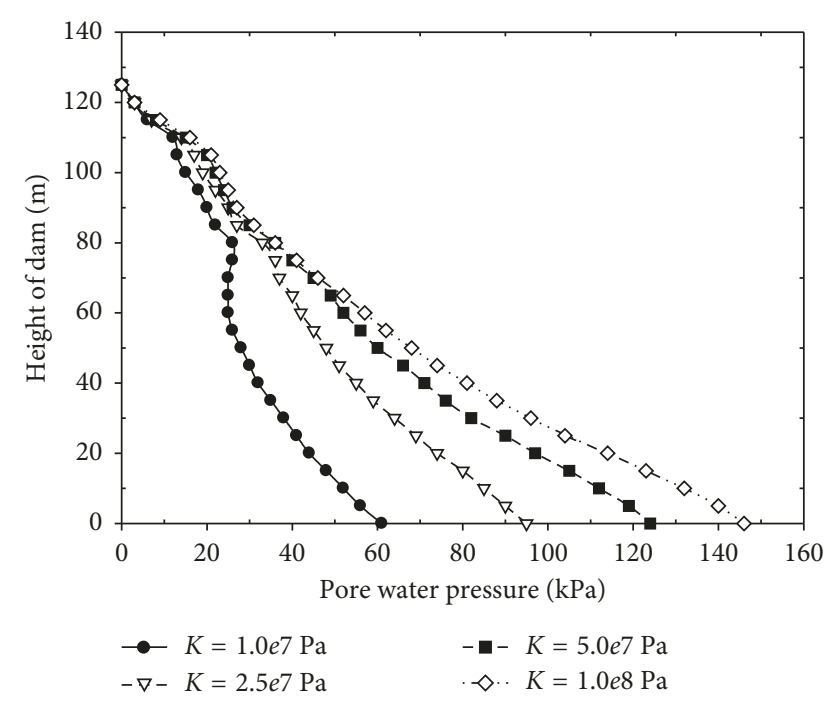

FIGURE 9: Comparing the pore water pressure values for different bulk modulus of water.

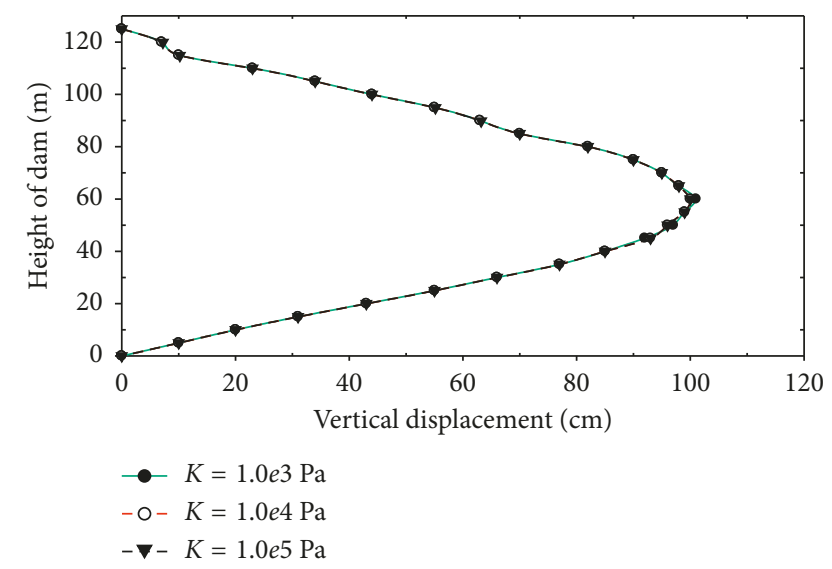

FIGURE 10: Comparing the displacement values in the middle of the core for different bulk modulus of water in the water-flow stage.

phase in the following stage without considering the mechanical behavior of the soil environment, through examining the pressure equation. This process will be repeated for each layer in construction and impounding, and the satisfactory answers will be eventually obtained. Therefore, the consolidation process of the dam will be finally modeled through using this method during construction and impounding.

The point to be noted in this analysis, which has also been mentioned in the software instructions, is that the program is sensitive to the value of the bulk modulus of water in the analysis time in the stage of water-flow analysis, and the run-time also proportionately increases as the bulk modulus increases. This is because the number of the essential stages for reaching the necessary flow time for constructing or impounding each layer proportionately increases for bulk modulus with larger numbers, and if the bulk modulus of water increases by 10 times, the number of the stages must also increase by 10 times, so the satisfactory

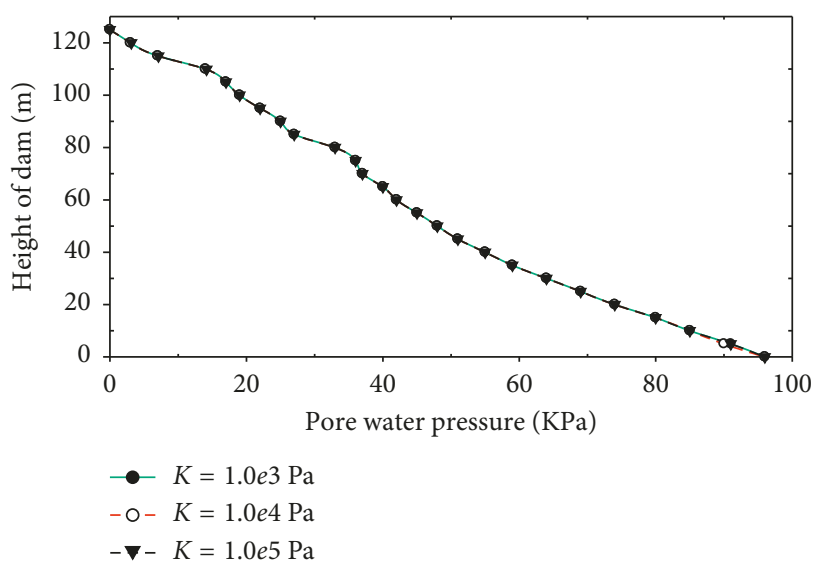

FIGURE 11: Comparing the pore water pressure values for different bulk modulus of water in the water-flow stage.

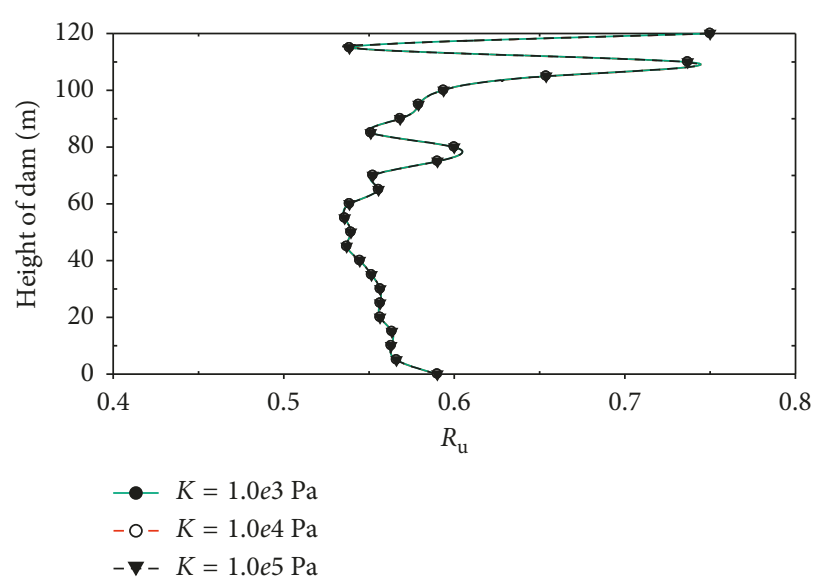

FIgURE 12: Comparing $R_{\mathrm{u}}$ for different bulk modulus of water in the water-flow stage.

time is obtained. On the other hand, selecting bulk modulus of water has no effect on the accuracy of the results according to Figures 10-12 which is in the water-flow stage due to the mechanical analysis of the model. Therefore, the bulk modulus of water could be first considered equal to the value obtained from unsaturated soil analysis in each stage for mechanical solution. A lower bulk modulus of water could be considered for the water-flow stage which is considered equal to $1 e 5 \mathrm{~Pa}$ here.

\section{Summary}

(i) The number of the dam's layers is equal to its elements in the vertical direction in time of construction and in numerical calculations; otherwise, the results of the vertical dispositions or the settlement of the dam will be unorderly, fluctuated, and unreal.

(ii) Correlated analysis is a more accurate method in comparison with the uncorrelated analysis, but this analysis requires a lot of time and computational 
effort in order to be run and present results. These times will increase progressively as the number of the elements increase. Therefore, this analysis is not economical for dams over 100 meters high, and the alternative method is uncorrelated analysis.

(iii) Examining the degree of accuracy of the number of elements in the results of the numerical analysis made it clear that making the elements tiny and increasing their number from 1300 elements to 7200 elements will decrease the total vertical stress and pore water pressure ratio about 2 and 3 percent, respectively, and vertical displacement increases 4 percent.

(iv) The compressible fluid method can be used in the unsaturated state of the dam's core during construction and impounding, and the equivalent bulk modulus of liquid-air phase must be obtained for that purpose since the obtained answers will depend on them.

(v) With regard to the parametric studies conducted on bulk modulus of water in the compressible fluid method, it became clear that the displacements are not that sensitive to bulk modulus of water and only the dam's settlement locations transfers to a location higher than the dam core as the bulk modulus of water increases. However, pore water pressure is extremely sensitive to bulk modulus of water.

\section{Conflicts of Interest}

The authors declare that they have no conflicts of interest.

\section{References}

[1] J. Zeller and R. Wullimann, "The shear strength of the shell materials for the Ge-Schenenalp dam, Switzerland," in Proceedings of the 4th International Conference on SMFE, pp. 399-404, London, UK, August 1957.

[2] J. Lowe, "Shear strength of coarse embankment dam materials," in Proceedings of the 8th International Congress on Large Dams, pp. 745-761, Edinburgh, UK, May 1964.

[3] E. Fumagalli, "Tests on cohesion less materials for rockfill dams," Journal of Soil Mechanics and Foundation, ASCE, vol. 95, no. 1, pp. 313-332, 1969.

[4] C. Tirado, K. Y. Rios-Gomes, A. Fathi, M. Mazari, and S. Nazarian, "Simulation of light weight deflectometer measurements considering nonlinear behavior of geomaterials," Transportation Research Record: Journal of the Transportation Research Board, vol. 2641, pp. 58-65, 2017.

[5] T. Ramamurthy and K. K. Gupta, "Response paper on how one ought to determine soil parameters to be used in design of earth and rockfill dams," in Proceedings, Indian Geotechnical Conference, pp. 15-19, New Delhi, India, December 1986.

[6] T. Valstad, P. B. Selness, F. Nadim, and B. Aspen, "Seismic response of a rockfill dam with an asphaltic concrete core," International Journal of Rock Mechanics and Mining Sciences and Geomechanics Abstracts, vol. 28, no. 5, p. 320, 1991.

[7] K. Hoeg, Asphaltic Concrete Cores for Embankment Dams, Norwegian Geotechnical Institute of Technology, Oslo, Norway, 1993.
[8] H. A. C. Meintjes and G. A. Jones, "Dynamic analysis of Ceres dam," in Proceedings of the 12th Regional Conference for Africa on Soil Mechanics and Geotechnical Engineering, Durban, South Africa, October 1999.

[9] M. Rashidi and S. M. Haeri, "Evaluation of the behavior of earth and rockfill dams during construction and first impounding using instrumentation data and numerical modeling," Journal of Rock Mechanic and Geotechnical Engineering, vol. 9, no. 4, pp. 709-725, 2017.

[10] M. Rashidi, M. Heidar, and G. Azizyan, "Numerical analysis and monitoring of an embankment dam during construction and first impounding (case study: Siah Sang Dam)," Scientia Iranica, vol. 25, no. 2, pp. 505-516, 2018.

[11] M. H. S. Salemi and Baziar, "Dynamic response analysis of a rockfill dam with asphalt concrete core," in Proceedings of Soil and Rock American Conference, Boston, MA, USA, June 2003.

[12] S. Feizi-Khankandi, A. A. Mirghasemi, A. Ghalandarzadeh, and K. Hoeg, "2D nonlinear analysis of asphaltic concretecore embankment dams," in The 12th International Conference of International Association for Computer Methods and Advances in Geomechanics (IACMAG), Goa, India, October 2008.

[13] A. Taghavi Ghalesari and A. Janalizadeh Choobbasti, "Numerical analysis of settlement and bearing behaviour of piled raft in Babol clay," European Journal of Environmental and Civil Engineering, vol. 22, no. 8, 2016.

[14] A. Barari, L. B. Ibsen, A. Taghavi Ghalesari, and K. A. Larsen, "Embedment effects on vertical bearing capacity of offshore bucket foundations on cohesionless soil," International Journal of Geomechanics, vol. 17, no. 4, article 04016110, 2017.

[15] M. Rashidi, S. R. Ashtiani, J. Si, R. P. Izzo, and M. McDaniel, "A practical approach for the estimation of strength and resilient properties of cementitious materials in the laboratory," Transportation Research Record: Journal of the Transportation Research Board, article 0361198118769900, 2018. 


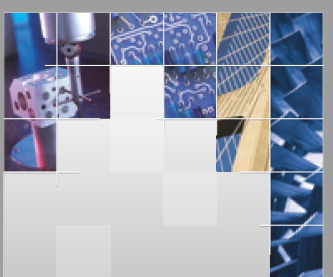

\section{Enfincering}
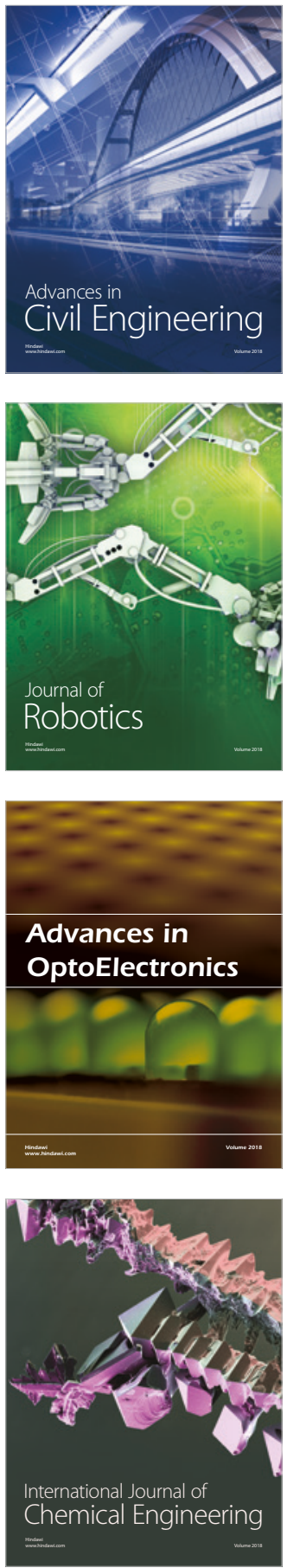

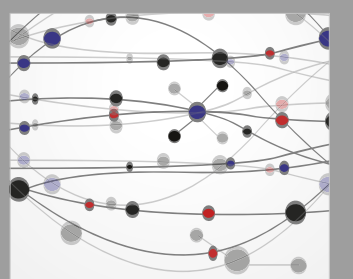

\section{Rotating \\ Machinery}

The Scientific World Journal

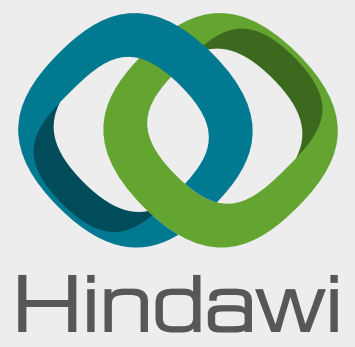

Submit your manuscripts at

www.hindawi.com
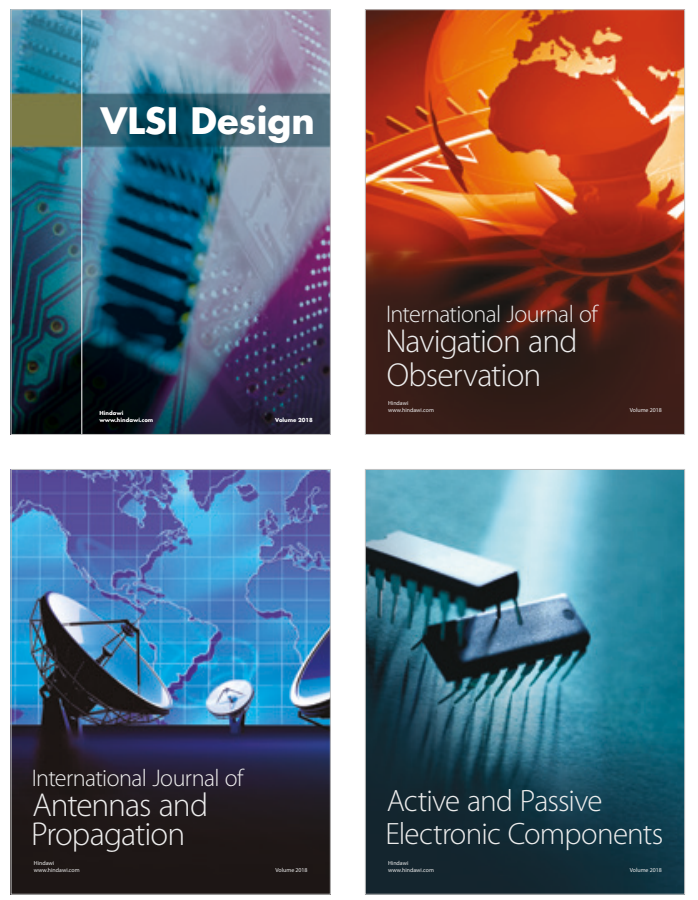
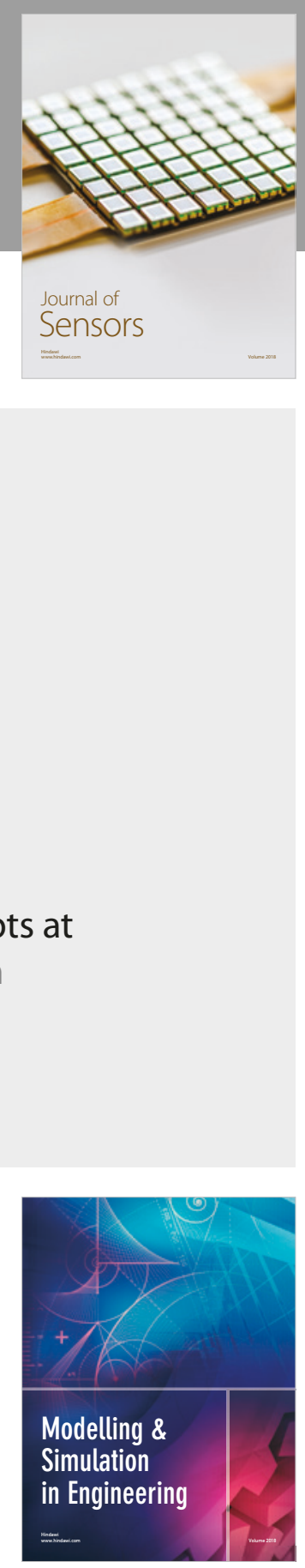

\section{Advances \\ Multimedia}
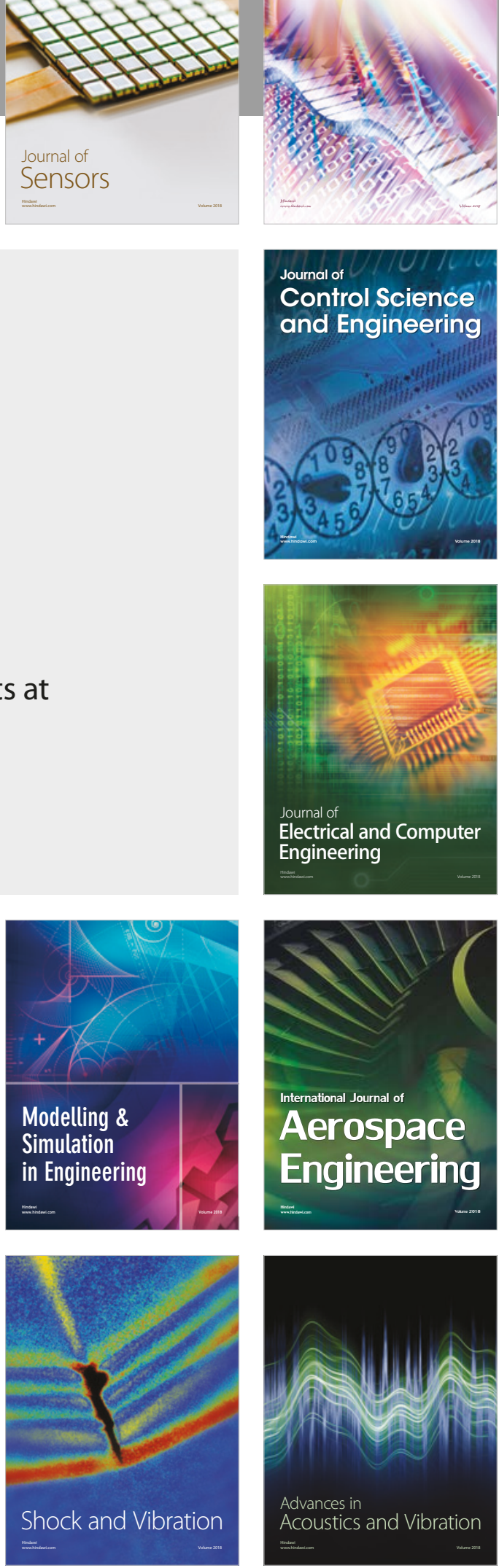